\title{
Chronic Kidney Disease Among Hypertensive Patients: Need for Screening Programmes
}

\author{
Silvana Nader Nagib" ${ }^{1}$, Saeed Abdelwahab ${ }^{2}$, Ghada Essam El Din Amin ${ }^{3}$ and Mohamed Farouk \\ Allam $^{1 *}$ \\ ${ }^{1}$ Department of Family Medicine, Faculty of Medicine, Ain Shams University
}

${ }^{2}$ Department of Internal Medicine and Nephrology, Faculty of Medicine, Ain Shams University

${ }^{3}$ Department of Community, Environmental and Occupational Medicine, Faculty of Medicine, Ain Shams University

*Corresponding author: Mohamed Farouk Allam, Department of Family Medicine, Faculty of Medicine, Ain Shams University, 11566 Abbasia, Cairo, Egypt.

To Cite This Article: Silvana Nader N, Saeed A, Ghada Essam El Din A, Mohamed Farouk A. Chronic Kidney Disease Among Hypertensive Patients: Need for Screening Programmes. Am J Biomed Sci \& Res. 2021 - 11(4). AJBSR.MS.ID.001656. DOI: 10.34297/AJBSR.2021.11.001656.

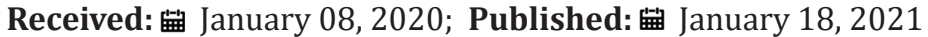

\begin{abstract}
Chronic kidney disease (CKD) has a high morbidity and mortality rates and costs a lot of money including health care, haemodialysis costs and management of complications of CKD. Patients with more progressive stages 3 and 4 CKD experience a high incidence of cardiovascular events and death compared with stages 1 and 2 of CKD. According to the Global Burden of Disease Study conducted in 2010, CKD became the 18th place on a list of the greatest causes of deaths in the world, with an annual mortality rate of 16.3 per 100,000 people. Due to the high prevalence of diabetes, hypertension and coronary artery disease, CKD became world widespread. In alignment with the presence of metabolic and cardiovascular diseases, the prevalence of hypertensive nephropathy prevalence is $7.75 \%$. Unfortunately, the number of patients started to develop end stage renal disease because of hypertension is exceeding. Hypertension-induced renal damage includes the systemic blood pressure load, the degree of renal microvasculature affection, and local susceptibility factors to barotrauma, all of which are affected by the degrees of hypertension. Therefore, in developing countries, screening programmes are extremely needed to detect the early stages of CKD among hypertensive diabetics and non-diabetic patients attending primary healthcare centres.
\end{abstract}

Keywords: Screening, Health Programmes, Chronic Kidney Disease, Hypertension, Primary healthcare centres

\section{Mini-Review}

Chronic kidney disease (CKD) affects approximately 13\% of the adult population. Unfortunately, CKD has a high morbidity and mortality rates and can cost the government a lot of money due to the haemodialysis and management of complications of CKD. Patients with more progressive stages 3 and 4 CKD experience a high incidence of cardiovascular events and death compared to stages 1 and 2 of CKD [1]. Although, more than $90 \%$ of individuals who have CKD remain unrecognized, diabetes mellitus and hypertension are the major risk factors of CKD, respectively. Therefore, early screening and prevention of progression of CKD are one of the major challenges and goals for primary care physicians to avoid the high incidence of cardiovascular events [2].
CKD represents a decrease in glomerular filtration rate (GFR) in a progressive and irreversible manner [3]. Unfortunately, no specific treatment for most of the chronic nephropathies and they tend to progress spontaneously to end-stage renal disease (ESRD). Whatever the underlying aetiology of the kidney disease, progressive renal function loss is a common and shared phenomenon in renal failure.

In the past, The National Kidney Foundation - Kidney Disease Outcomes Quality Initiative (NKF-KDOQI) workgroup has defined CKD as the anatomical or functional aberrations of the kidney with or without decreased glomerular filtration rate (GFR) that, manifested by either aberration in the blood or urine composition, 
or changes in imaging tests and/ or the presence of GFR $<60 \mathrm{ml} /$ $\min /(1.73 \mathrm{~m} 2)$ for three months, with or without other signs of kidney damage as described above [4].

However, recently the Kidney Disease Improving Global Outcomes 2012 (KDIGO 2012) [5] has defined CKD as aberrations of renal structure or function, present for $>3$ months, with implications for health. They classified the stages of CKD into five stages according to the eGFR as follows:

1. Stage 1: GFR $\geq 90 \mathrm{~mL} / \mathrm{min} / 1.73 \mathrm{~m}^{2}$ (normal or high).

2. Stage 2: $\mathrm{GFR}=60-89 \mathrm{~mL} / \mathrm{min} / 1.73 \mathrm{~m}^{2}$ (Mildly decreased).

3. Stage 3a: $\mathrm{GFR}=45-59 \mathrm{~mL} / \mathrm{min} / 1.73 \mathrm{~m}^{2}$ (Mildly to moderate decreased).

4. Stage 3b: $\mathrm{GFR}=30-44 \mathrm{~mL} / \mathrm{min} / 1.73 \mathrm{~m}^{2}$ (Moderate to severely decreased).

\section{Stage 4: $\mathrm{GFR}=15-29 \mathrm{~mL} / \mathrm{min} / 1.73 \mathrm{~m}^{2}$ (Severely decreased).}

6. Stage 5: GFR $<15 \mathrm{~mL} / \mathrm{min} / 1.73 \mathrm{~m}^{2}$ (Kidney failure).

KDIGO (2012) established new diagnostic criteria for diagnosis of CKD that involves abnormalities in one of the following markers for $>3$ months:

1. Albuminuria (albumin excretion $>30 \mathrm{mg} / 24 \mathrm{hr}$ or albumin: creatinine ratio $>30 \mathrm{mg} / \mathrm{g}[>3 \mathrm{mg} / \mathrm{mmol}]$.

2. Urine sediment abnormalities (RBCs casts, WBCs casts, hyaline casts).

3. Electrolyte disturbance and other abnormalities due to tubular disorders.

4. Histologic abnormalities by renal biopsy.

5. Structural abnormalities detected by ultrasound imaging or

6. History of kidney transplantation in such cases [5].

In the USA, it is estimated that $18 \%$ of the adult population, roughly 28 million individuals, showed different stages of CKD in 2007. In the elderly, the mean prevalence of CKD tends to increase and can reach up to 36\%. According to Global Burden of Disease Study conducted in 2010, CKD occupied 18th place on a list of the greatest causes of death in the world, with an unexpected annual mortality rate of 16.3 per 100,000 people [6].

In the Middle East, there is still lack of data conducted on the prevalence and risk factors for microalbuminuria (MA) and CKD. In the United Arab Emirates (UAE), due to the exceeding prevalence of diabetes, hypertension and coronary artery disease,
CKD became world widespread. Following the era of metabolic and cardiovascular diseases (CVDs) appearance, the prevalence of hypertensive nephropathy prevalence is $7.75 \%$. Subgroup analysis by location showed that prevalence of hypertensive nephropathy in Saudi Arabia was found to be $20.08 \%, 10.56 \%, 8.13 \%$ and $6.9 \%$ in the central region, Eastern region, Western region, and Southern region respectively [7].

In Egypt, when a cross-sectional study from communitybased screening programme was conducted on the relatives of CKD patients to detect the prevalence and risk factors for microalbuminuria (MA), it was found that the prevalence of MA, was more than $10 \%$ in the population screened and in the participants with diabetes, hypertension, obesity, or CVDs tends to be higher [8].

Unfortunately, the number of patients who started to develop ESRD is rising in Egypt as a complication of hypertension. However, the diagnosis of hypertensive ESRD is done by exclusion and this classification does not depend on any pathological data. These patients suffer from a wide variety of diseases, including accelerated hypertension and atherosclerotic disease of the large arteries and undiagnosed chronic renal disease. Patients suffering from mild-to moderate hypertension are recognized to develop ESRD. Therefore, studies conducted to determine the frequency of ESRD due to essential hypertension are lacking in Egypt and additional studies needed to be conducted for that purpose [9].

Hypertension-induced renal damage includes the systemic blood pressure load, the degree of renal microvasculature affection, and local susceptibility factors to barotrauma, all of which are affected by the degrees of hypertension. The result is that hypertension enhances the progression of renal disease deterioration directly by worsening glomerular injury and proteinuria, which leads to further glomerular and tubulointerstitial injury, thus simulation of GFR fall [10].

Screening for CKD is supposed to be a priority for primary care and health care physicians to slow down the deterioration of kidney function and the progression towards the ESRD, they should be aware of any abnormalities in kidney functions for early treatment of CKD and its complications. It is better for general practitioners or family doctors (GPs/FDs) to carry out screening, as most of the population visits their GP/FD within a 3-year period and can be subject to screening. The high-risk group that should be screened for CKD includes those with hypertension, diabetes, recurrent urinary tract infections, urinary obstruction, systemic diseases, or autoimmune diseases that affect kidneys and/or past or family history of hypertension, diabetes, or cardiovascular disease [11].

Screening of high-risk population may help early detection of any renal diseases by GPs/FDs and provide the utilization 
of essential integrated action systems to halt and avoid the deterioration of hypertensive or diabetic nephropathy that occur over numerous years [11-16].

Therefore, in developing countries, screening programmes are extremely needed to detect the early stages of CKD among hypertensive diabetics and non-diabetic patients attending primary healthcare centres.

\section{References}

1. Ots M, Pechter U, Tamm A. Characteristics of progressive renal disease. Clinica Chimica Acta 2000; 297: 29-41

2. Alemán-Vega G, Cabañas IG, Sastre LR, Martín JR, Polentinos-Castro E, Barrientos RR. Prevalencia y riesgo de progresión de enfermedad renal crónica en pacientes diabéticos e hipertensos seguidos en atención primaria en la Comunidad de Madrid. Nefrología (Madrid) 2017; 37(3): 343-345.

3. Webster AC, Nagler EV, Morton RL, Masson P. Chronic Kidney Disease. Lancet 2017; 389(10075): 1238-1252.

4. Levey AS, Eckardt KU, Tsukamoto Y, Levin A, Coresh J, Rossert J, De Zeeuw D, Hostetter TH, Lameire N, Eknoyan G. Definition and classification of chronic kidney disease: a position statement from Kidney Disease: Improving Global Outcomes (KDIGO). Kidney Int 2005; 67(6): 20892100.

5. KDIGO Clinical Practice Guideline for the Management of Blood Pressure in Chronic Kidney Disease. Kideny International Supplements 2012; 2(5): 337-414.

6. Coresh J, Selvin E, Stevens LA, Manzi J, Kusek JW, Eggers P, et al. Prevalence of chronic kidney disease in the United States. J Am Med Assoc 2007; 298: 2038-2047.

7. Hassanien AA, Al-Shaikh F, Vamos EP, Yadegarfar G, Majeed A Epidemiology of end-stage renal disease in the countries of the Gulf Cooperation Council: a systematic review. JRSM short rep 2012; 3(6): $1-21$.
8. Gouda Z, Mashaal G, Bello AK, El Attar A, El Kemmry T, El Reweny A, El Nahas M. Egypt information, prevention, and treatment of chronic kidney disease (EGIPT-CKD) programme: Prevalence and risk factors for microalbuminuria among the relatives of patients with CKD in Egypt. Saudi J Kidney Dis Transpl 2011; 22(5): 1055-1063.

9. Soliman AR, Fathy A, Roshd D. The Growing Burden of End-Stage Renal Disease in Egypt. Renal Failure 2012;34(4): 425-428.

10. Ravera M, Re M, Deferrari L, Vettoretti S, Deferrari G. Importance of blood pressure control in chronic kidney disease. J Am Soc Nephrol 2006; 17(4 Suppl 2): S98-103.

11. Managing chronic kidney disease in primary care: a national consensus statement. 2014. Available at: http://www.rnzcgp.org.nz (Last accessed May 15, 2019).

12. Farag YM, Kari JA, Singh AK. Chronic kidney disease in the Arab world: a call for action. Nephro Clinica Pract 2012; 121(3-4): c120-123.

13. Mitra PK, Bradley JR. Chronic kidney disease in primary care. J R Soc Med 2007; 100: 40-45

14. Rosenberg M, Kalda R, Kasiulevicius V, Lember M; European Forum for Primary Care. Management of chronic kidney disease in primary health care: position paper of the European Forum for Primary Care. Qual Prim Care 2008; 16(4): 279-294.

15. Whelton PK, Carey RM, Aronow WS, Casey DE Jr, Collins KJ, Dennison Himmelfarb C, DePalma SM, Gidding S, Jamerson KA, Jones DW, MacLaughlin EJ, Muntner P, Ovbiagele B, Smith SC Jr, Spencer CC, Stafford RS, Taler SJ, Thomas RJ, Williams KA Sr, Williamson JD, Wright JT Jr. 2017, ACC/AHA/AAPA/ABC/ACPM/AGS/APhA/ASH/ASPC/NMA/PCNA Guideline for the Prevention, Detection, Evaluation, and Management of High Blood Pressure in Adults: A Report of the American College of Cardiology/American Heart Association Task Force on Clinical Practice Guidelines. J Am Coll Cardiol 2018; 71(19): 127-248.

16. National Kidney Foundation K/DOQI clinical practice guidelines for chronic kidney disease: evaluation, classification, and stratification. Am J Kidney Dis 2012; 60(5): 692-693. 